\title{
秦巴山区村域稳定脱贫测度及返贫防控风险识别 以重庆市城口县为例
}

\author{
郭 倩 ${ }^{1}$, 廖和平 ${ }^{1,2 *}$, 王子㑭 ${ }^{1}$, 刘愿理 ${ }^{1}$, 李 涛 $^{1}$ \\ (1. 西南大学地理科学学院, 重庆 400715; 2. 西南大学精准扶贫与区域发展研究中心, 重庆 400715)
}

\begin{abstract}
摘 要: 深度贫困地区农村实现稳定脱贫、建立返贫防控机制是后 2020 时代的现实要求, 更是精准扶贫与乡村振兴 承上启下的紧密衔接。以强度生态脆弱与集中连片特困复合地区重庆市城口县为研究区域, 基于脱贫稳定性测度 模型、障碍度模型和最小方差模型等方法对城口县 60 个行政村、1950 个农户进行多维脱贫稳定性空间分异特征和 返贫风险模式探究。研究发现: 1 样本村脱贫稳定性等级分布总体呈现前端窄小、中部突出的“葫芦状”结构, 各 地区多维脱贫稳定性总体不高且存在空间异质性; (2) 城口县返贫风险可识别为双风险模式、三风险模式、四风险 模式和五风险模式 4 种模式及各阻力因素多元整合主导的 11 种返贫风险类型, 人力资本、发展机会等涉及农户可 持续增收、动态抗风险能力及内生动力的要素逐渐成为现阶段返贫防控及减贫路径依赖的重点; (3) 立足区域特 征, 把继续攻坚和稳定脱贫、防止返贫摆在同等重要位置上, 因村施策提高群众抗风险能力, 精准织密防止脱贫群 体的返贫网。
\end{abstract}

关键 词: 村域; 稳定脱贫; 返贫风险模式; 空间分异; 后 2020 时代; 秦巴山区

贫困现象具有全球性、易发性、区域差异性等 复杂特征, 对全面提高人民生活水平和推动社会和 谐发展存在阻碍, 牵引着社会各界的广泛关注。中 国作为世界上最大的发展中国家, 改革开放以来开 展大规模扶贫开发且成效显著, 自 2014年实施精准 扶贫战略以来, 从绝对贫困人口 7071 万减至 2020 年底现行标准下农村贫困人口全部脱贫 ${ }^{[1]}$, 为世界 减贫事业做出了巨大贡献。目前, 农村贫困形态已 由经济水平落后、政策制度缺失转变为资源要素制 约和农户个体能力受限 ${ }^{[2-3]}$ 。为进一步消除中国农 村贫困化的空间孤岛效应和马太效应, 帮扶工作机 制也由“大水漫灌”的普惠式帮扶向 “精准滴灌” 的 精准式帮扶转变 ${ }^{[-5]}$ 。然而脱贫户仍存在内生发展 动力不足、持续增收困难和返贫现象频发 ${ }^{[6]}$ 等现象,
形成了新时期特殊的贫困内核。受资源禀赋、区位 差异、可获得性等要素综合影响,亟需拟合多维度 对贫困人口脱贫稳定性进行深人探析。

20 世纪 90 年代世界各国对贫困标准的判定多 停留在收人层面 ${ }^{[7]}$ 。随着对贫困认知及内涵的不断 深化, 以 Deutsch 为代表的学者指出收人仅作为衡 量贫困的重要代理变量,并不能全面反映真实的贫 困状况 ${ }^{[8-9]}$ 。部分学者从空间特征、地理资本、社会 政治等多个维度对 “空间贫困陷阱”进行了概念解 读 ${ }^{[10-12]}$; Park 等 ${ }^{[13]}$ 通过扶贫瞄准范围与贫困识别精度 的关联效应,探析其引发的社会问题。中国自 1986 年实施大规模反贫困后, 社会各界对贫困问题展开 持续关注和研究,贫困地理学也随着脱贫实践蓬勃 发展。从时间进程来看, 理论界研究方向及进展与

收稿日期: 2020-03-24; 修订日期: 2020-07-01。

基金项目: 教育部人文社会科学研究青年基金项目(20XJCZH005)。[Foundation: The Project of Humanities and Social Science Youth Fund of Ministry of Education, No. 20XJCZH005. ]

第一作者简介: 郭倩(1996-),女,陕西西安人,硕士生,主要从事土地利用与国土规划、乡村贫困治理研究。 E-mail: 18691367221@163.com

*通信作者简介: 廖和平 $(1964-)$, 女, 重庆璧山人, 教授,博士生导师,主要从事土地利用与区域可持续发展,减贫发展与乡村 振兴研究。E-mail: liaohp@swu.edu.cn

引用格式: 郭倩, 廖和平, 王子羿, 等. 秦巴山区村域稳定脱贫测度及返贫防控风险识别: 以重庆市城口县为例 [J]. 地理科学进展, 2021, 40(2): 232-244. [Guo Qian, Liao Heping, Wang Ziyi, et al. Measurement of rural poverty alleviation sustainability and return-to-poverty risk identification in Qinling-Bashan Mountains: A case study of Chengkou County, Chongqing Municipality. Progress in Geography, 2021, 40(2): 232-244. ] DOI: 10.18306/dlkxjz.2021.02.005 
实践界反贫困推进程度密不可分, 大致可分为 3 类: (1) 反贫困初期,即开发式扶贫和全面扶贫时期对贫 困概念及内涵的界定划分 ${ }^{[14-16]}$; 2) 反贫困中期,实施 精准扶贫战略前后关于贫困测度 ${ }^{[17-18]}$ 、分布特征 ${ }^{[19-21]}$ 影响因素 ${ }^{[22-24]}$ 等研究交叉迸发, 同时有学者通过治 理成效分析, 针对扶贫过程中出现的返贫、脱贫不 稳等问题提出政策建议 ${ }^{[25]}$; (3) 反贫困后期, 即后 2020 时期随着区域性整体贫困问题的逐步解决, 关

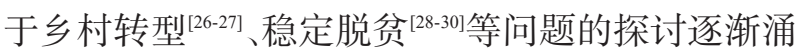
现, 为脱贫稳定性的研究提供了前瞻性指导。

通过国内外研究现状梳理发现, 目前稳定脱贫 的相关研究尚少且多基于大中尺度的定性分析。 如何科学有效地防止返贫、实现稳定脱贫给探讨现 阶段贫困治理提出了新的课题。鉴于此, 本文选取 强度生态脆弱与集中连片特困复合地区一一秦巴 山区重庆市城口县为例, 以全县 60 个样本村为研究 区、以各村境内抽样农户为研究对象, 从村域尺度、 农户视角对稳定脱贫进行阐释及测度, 识别返贫风 险, 试图找出山区脱贫稳定性分异特征及返贫风险 类型, 为因地制宜制定脱贫长效机制、实现稳定脱 贫提供决策参考。

\section{1 稳定脱贫的科学内涵}

确保贫困对象实现稳定脱贫, 既是中国精准扶 贫政策的逻辑延续, 也是新时代实现 “两步走” 战略 目标的重要基础。现阶段贫困问题可分为原生贫 困问题和再生贫困问题(即重返贫困), 解决原生贫 困问题、防范再生贫困问题是实现稳定脱贫的必由 之路 ${ }^{[31]}$ 。杨龙等 ${ }^{[32]}$ 认为返贫脆弱性是农户未来陷人 贫困的可能原因; 吴仪等 ${ }^{[33]}$ 从多维视角构建返贫脆 弱性评价指标体系, 揭示返贫脆弱性时空格局与产 生机制; 王富珍等 ${ }^{[34]}$ 将贫困脆弱性与脱贫稳定性背 景相结合, 以可持续生计理论为框架对农户脱贫稳 定程度进行探究。上述研究都为稳定脱贫测度提 供了思路和借鉴。

为此, 本文在已有研究成果的基础上, 关注农 户个体脱贫能力的同时关注脆弱性背景和潜在风 险冲击, 从多维视角对稳定脱贫进行重新梳理和 界定: 认为稳定脱贫是在贫困地区基础设施和公 共服务设施不断完善的基础上,脱贫户所处的宏微 观生存环境得到改善, 收人来源具有可靠性及稳定
性, 创收能力及发展观念不断增强, 社会保障力度 不断提升, 同时具有一定承受家庭及外部风险冲击 的能力。即贫困脆弱性不断降低, 脱贫稳定性显著 升高(图1)。

\section{2 研究区概况与数据来源}

\section{1 研究区概况}

城口县是重庆市下辖国家级重点贫困县之一, 地处重庆市东北部、渝川陕三省(市)交界处, 素有 “鸡鸣三省”之称; 位于秦巴山区大巴山南麓, 属大 巴山弧形断褶带的南缘部分, 由一系列西北至东西 走向的雁列式禇皱和冲断层组成,地势南东偏高、 北西偏低，山地与丘陵占全县总面积的 70\% $80 \%$ (图2)。该区受自然地理因素和社会经济地理因素 的双重影响,集“老、边、山、穷”于一体, 远离主城 区, 交通闭塞, 经济落后, 山洪灾害频发,贫困程度 较深、脱贫难度较大, 作为重庆市和全国扶贫开发 的重点县域, 针对该地区进行稳定脱贫测度和返贫 防控机制研究具有重要的理论与现实意义。

\section{2 数据来源}

本文采取“乡镇一行政村一农户”三级分层抽 样与随机抽样相结合的方式, 覆盖城口县所有乡 镇, 以 60 个样本村为研究区域, 以区域内 1950 个贫 困农户为研究对象, 主要涉及土地利用、社会经济 和农户调查等方面数据,所有基础地理数据均经过 粗差剔除和地理校正,时间节点为 2019年。数据主 要来源与处理如下:

(1) 土地利用数据包含村域耕地面积等统计数 据和耕地图斑、坡度等矢量数据。耕地的平均坡度 通过 ArcGIS 坡度分析获取, 主要由城口县国土资 源局提供土地利用变更数据。

(2) 调研数据主要来源于 2019 年精准扶贫第三 方评估实地调研, 调研以户为基本单位, 主要内容 涉及农户经济条件、人力资本、发展机会和社会保 障等基础信息, 其中有效样本量 1900 份。包含贫困 家庭收支明细、住房条件、产业发展水平、劳动力数 量及质量、健康状况、劳动力转移就业、医疗教育条 件、交通便利程度、参与技能培训、政策性贷款情况 等计量数据, 并通过计算获取各项指标占比。村域 层面的数据计算方式为, 以贫困农户各维度组成指 标在村域层面的平均值进行加权求和 ${ }^{[35]}$ 。 


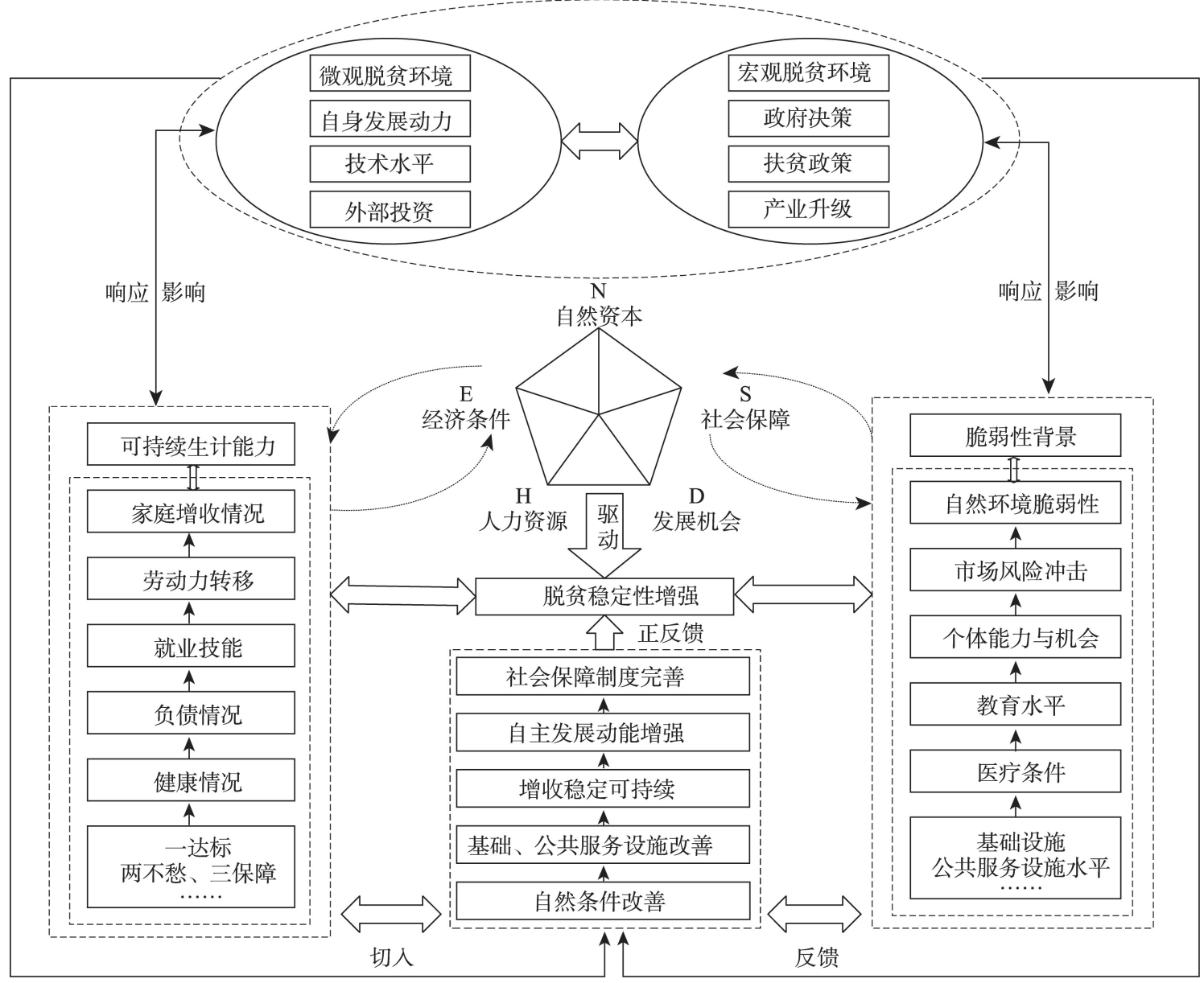

图 1 稳定脱贫的概念和内涵

Fig.1 Concept and connotation of sustainable poverty alleviation

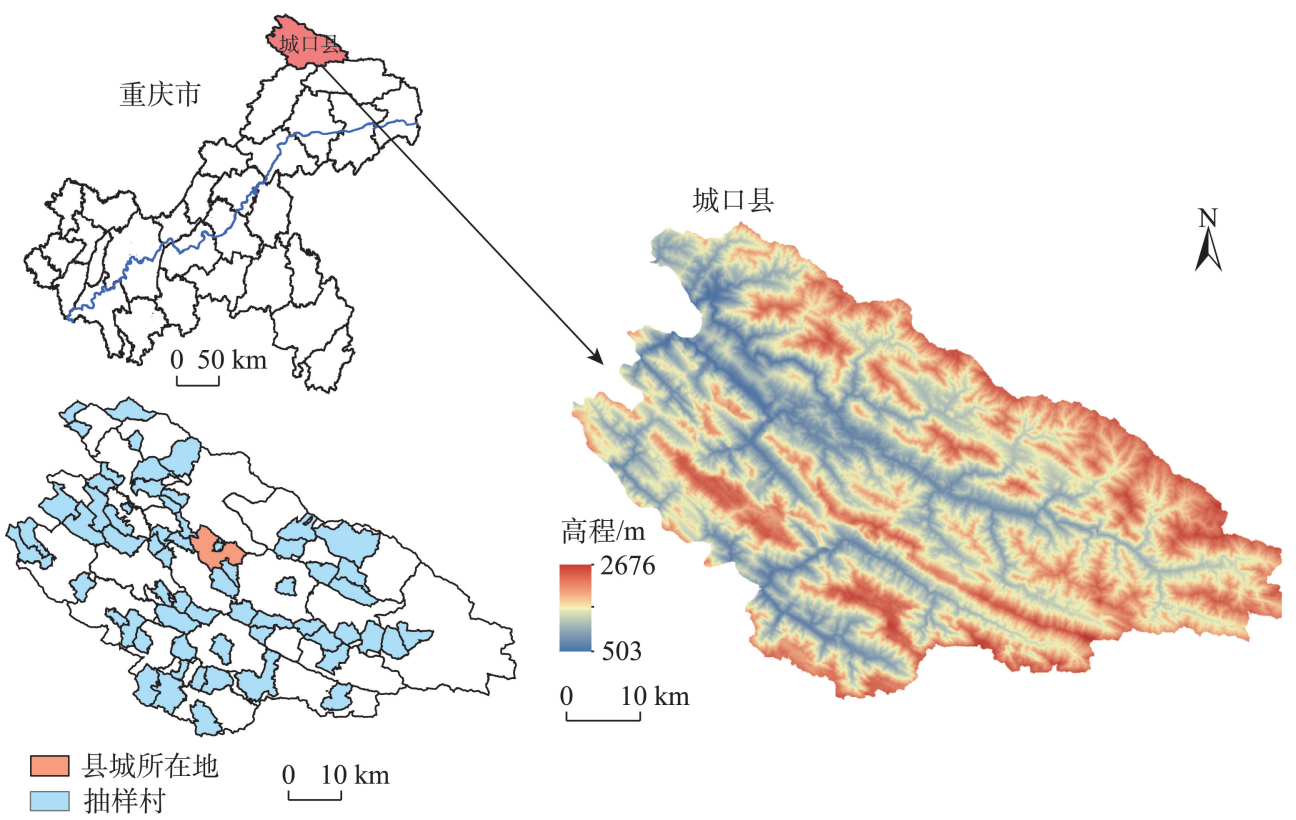

图 2 城口县地形及方位图

Fig.2 Terrain and location of Chengkou County 


\section{3 研究方法与评价指标体系构建}

\section{1 研究方法}

(1) 数据无量纲化处理

本文选取的评价指标存在量纲的差异, 在对样 本村进行脱贫稳定性测度之前需要对各项评价指 标的原始数据进行无量纲化处理。处理公式如下:

$$
\begin{aligned}
& \text { 正向指标: } Y_{i j}=\frac{X_{i j}-X_{j \min }}{X_{j \max }-X_{j \min }} \\
& \text { 负向指标: } Y_{i j}=\frac{X_{j \max }-X_{i j}}{X_{j \max }-X_{j \min }}
\end{aligned}
$$

式中: $Y_{i j}$ 为无量纲化处理后的指标值, $X_{i j}$ 为城口县第 $i$ 个样本村第 $j$ 项评价指标的原始数据, $X_{j \max } 、 X_{j \min }$ 分 别为第 $j$ 项评价指标的最大值和最小值。

(2) 脱贫稳定性指数测算

本文构建的村级脱贫稳定性评价指标体系由 自然资本、经济条件、人力资本、发展机会、社会保 障 5 个维度综合组成, 每个维度下分别设置了若干 评价指标, 通过维度综合权重对各维度进行加权求 和,求得研究区脱贫稳定性指数。计算公式 ${ }^{[36]}$ 如下：

$$
\text { MPASI }=\sum_{i=1}^{\alpha}\left(\sum_{j=1}^{\beta} Y_{i j} W_{i j}\right) W_{i}
$$

式中:MPASI 为村级多维脱贫稳定性指数; $\alpha$ 为维度 个数; $\beta$ 为相应维度下的指标个数; $W_{i j}$ 为指标权重; $W_{i}$ 为维度权重。MPASI $\in[0,1]$ 。

(3) 障碍度模型和最小方差模型

在稳定脱贫的评价过程中,不仅要对脱贫稳定 性水平进行测度, 了解不同地区贫困控制过程中的 阻碍因素同样至关重要, 以便对村域返贫风险进行 病理性诊断。因此,本文将障碍度模型及最小方差 模型(least square error, LSE)引人返贫风险管理,对 脱贫稳定性展开延伸性研究,试图探寻各村稳定脱 贫的阻力因素。利用多维度指标的返贫风险贡献 率, 系统划分各样本村的返贫风险模式 ${ }^{[37]}$ 。其计算 公式如下:

$$
C_{i}=\frac{W_{i j}=1-Y_{i j} \sum_{j=1}^{\beta} O_{i j} W_{i j}}{\sum_{i=1}^{a}\left(\sum_{j=1}^{\beta} O_{i j} W_{i j}\right) W_{i}}
$$

式中: $O_{i j}$ 指单因素指标与系统发展目标的偏离度, 此处设为单项指标标准化值与 $100 \%$ 之差; $C_{i}$ 为贫 困村 $i$ 维度因素对稳定脱贫的影响程度, 即返贫风
险贡献率。

$$
S^{2}=\frac{1}{n} \sum_{i=1}^{n}\left(x_{i}-\bar{x}\right)^{2}
$$

式中: $S^{2}$ 代表方差; $x_{i}$ 表示样本数据; $\bar{x}$ 为样本平均 值; $n$ 为样本量。当 $S^{2}$ 最小时, 实际维度返贫风险贡 献率分布与理论模型分布最接近, 子维度的个数即 是脱贫稳定性管理主要阻力个数, 该最小方差模型 即为样本村的返贫风险模式 ${ }^{[38]}$ 。因此, 理论上存在 “单风险模式”“双风险模式”“三风险模式”“四风险 模式”和“五风险模式”。

\section{2 维度与测度指标体系}

(1) 维度体系。本文以微观分析视角, 选取 5 个 一级指标、 21 个二级指标刻画城口县脱贫稳定性 (表 1)。其中: 自然资本 4 个 $\left(C_{1} \sim C_{4}\right)$ 、经济条件 5 个 $\left(C_{5} \sim C_{9}\right)$ 、人力资本 4 个 $\left(C_{10} \sim C_{13}\right)$ 、发展机会 5 个 $\left(C_{14} \sim C_{18}\right)$ 、社会保障3个 $\left(C_{19} \sim C_{21}\right)$ 。

(2) 指标权重的设定。本文在稳定脱贫概念与 内涵的基础上,结合实地调研数据,参考部分学者 的研究成果 ${ }^{[39-41]}$, 结合层次分析法(AHP) 和熵值法 $(E V W)$ 的特点 ${ }^{[42-44]}$, 共同确定各维度和各指标权重, 以期获取更符合实际情况的测算结果(表 1)。

\section{4 结果与分析}

\section{1 村域脱贫稳定性测度与区域分异机制}

根据脱贫稳定性测度模型(3)计算出城口县样 本村自然资本、经济条件、人力资本、发展机会、社 会保障 5 个维度的脱贫稳定性指数和多维脱贫稳定 性指数。在 ArcGIS 软件平台中利用自然断点法将 各村 5 个维度的脱贫稳定性指数及综合脱贫稳定性 指数划分为稳定、较稳定、一般稳定和较不稳定 4 个 等级。从表 2 可知,城口县样本村的多维脱贫稳定 性指数分布总体呈现前端窄小、中部突出的“葫芦 状”结构,较稳定和一般稳定的村落占比较大, 较不 稳定数量次之,脱贫稳定村占比较小,脱贫稳定性 总体不高且各村之间存在显著差异。

(1) 自然资本

城口县自然资本脱贫稳定性指数值位于 $0.251 \sim 0.741$ 之间,均值为 0.523 , 可以看出各村自然 资本差异较大,处于脱贫较不稳定、一般稳定、较稳 定、稳定的村分别占样本村总量的 $13.33 \%$ 、33.33\% 、 $41.67 \%$ 和 $11.67 \%$ 。自然资本维度脱贫稳定性较低 的区域集中分布在县城中部偏南和西北角,包括左 
表 1 脱贫稳定性多维测度指标体系

Tab.1 Multidimensional evaluation index of poverty alleviation sustainability

\begin{tabular}{|c|c|c|c|c|c|c|c|c|}
\hline 维度 & $\begin{array}{l}\text { 维度 } \\
\text { 权重 }\end{array}$ & 代码 & 指标 & $\begin{array}{c}\text { 指标阐释 } \\
\text { 及赋值 }\end{array}$ & $\begin{array}{l}\text { 指标 } \\
\text { 性质 }\end{array}$ & $\begin{array}{l}\text { 主观 } \\
\text { 权重 }\end{array}$ & $\begin{array}{l}\text { 客观 } \\
\text { 权重 }\end{array}$ & $\begin{array}{l}\text { 组合 } \\
\text { 权重 }\end{array}$ \\
\hline \multirow[t]{4}{*}{ 自然资本 } & 0.15 & $C_{1}$ & 平均海拔 & 村海拔 & - & 0.26 & 0.27 & 0.27 \\
\hline & & $C_{2}$ & 人均耕地数量 & 耕地面积/总人口(村) & + & 0.25 & 0.26 & 0.26 \\
\hline & & $C_{3}$ & 耕地质量 & 坡度大于 $25^{\circ}$ 耕地占比 & - & 0.25 & 0.23 & 0.23 \\
\hline & & $C_{4}$ & 地质灾害易发性 & 参照蒋佩华 ${ }^{[4]}$ 的研究成果 & - & 0.24 & 0.24 & 0.24 \\
\hline \multirow[t]{5}{*}{ 经济条件 } & 0.23 & $C_{5}$ & 住房条件 & $\begin{array}{l}2 \text { 处及以上住房 }=4 \text {, 钢混 } / \text { 砖混房 }=3 \text {, 砖瓦或砖木房 }=2 \text {, 土木房 } \\
\text { 及没有自有住房 }=1\end{array}$ & + & 0.20 & 0.19 & 0.20 \\
\hline & & $C_{6}$ & 增收情况 & 增收且可持续 $=3$,增收但不可持续 $=2$,未增收 $=1$ & + & 0.18 & 0.19 & 0.19 \\
\hline & & $C_{7}$ & 家庭人均年收人 & 家庭纯收人/家庭人口 & + & 0.28 & 0.30 & 0.29 \\
\hline & & $C_{8}$ & 转移性收人占比 & 政府补贴、亲友补助等收人/总收人 & - & 0.15 & 0.14 & 0.14 \\
\hline & & $C_{9}$ & 产业发展效果 & 帮扶效果明显 $=3$, 效果一般 $=2$, 没有效果 $/$ 未帮扶 $=1$ & + & 0.19 & 0.18 & 0.18 \\
\hline \multirow[t]{4}{*}{ 人力资本 } & 0.23 & $C_{10}$ & 劳动力比重 & 16 60 周岁(除学生外)有劳动能力人数/家庭人口 & + & 0.24 & 0.24 & 0.24 \\
\hline & & $C_{11}$ & 劳动力平均质量 ${ }^{[46]}$ & $\begin{array}{l}\text { 劳动力成员质量总得分/劳动力人数 (良好 }=4 \text {, 慢病 } / \text { 三四级残 } \\
\text { 疾 }=3 \text {, 大病 }=2, \text { 二级残疾 } / \text { 精神病 }=1 \text { ) }\end{array}$ & + & 0.26 & 0.27 & 0.26 \\
\hline & & $C_{12}$ & 健康状况 & 健康人口/家庭总人口 & + & 0.22 & 0.20 & 0.21 \\
\hline & & $C_{13}$ & 劳动力转移就业占比 & 劳动力转移就业人口/劳动力总人口 & + & 0.28 & 0.29 & 0.29 \\
\hline \multirow[t]{5}{*}{ 发展机会 } & 0.21 & $C_{14}$ & 政策性贷款支持/户 & 有且有明显帮助 $=3$, 有但帮助不明显 $=2$, 有但无帮助 $/$ 无 $=1$ & + & 0.17 & 0.16 & 0.17 \\
\hline & & $C_{15}$ & 劳动技能培训/户 & $\begin{array}{l}\text { 参加培训且有明显效果 }=3 \text {, 参加培训但效果不明显 }=2 \text {, 参加培 } \\
\text { 训但无效果或未参加 }=1\end{array}$ & + & 0.20 & 0.21 & 0.21 \\
\hline & & $C_{16}$ & 负债情况 & 无负债 $=3$,负债 1 万元及以下 $=2$,负债大于 1 万元 $=1$ & + & 0.23 & 0.25 & 0.24 \\
\hline & & $C_{17}$ & 交通便利程度 & 非常方便 $=3$,方便 $=2$, 不方便 $=1$ & + & 0.21 & 0.20 & 0.20 \\
\hline & & $C_{18}$ & 教育条件 & 非常方便 $=3$,方便 $=2$,不方便 $=1$ & + & 0.19 & 0.18 & 0.18 \\
\hline \multirow[t]{3}{*}{ 社会保障 } & 0.18 & $C_{19}$ & 看病就医条件 & 非常方便 $=3$,方便 $=2$,不方便 $=1$ & + & 0.40 & 0.41 & 0.40 \\
\hline & & $C_{20}$ & 医疗保险及救助 & 合作医疗 $=4$, 大病保险 $=3$, 大病或慢性病救助 $=2$, 其他保险 $=1$ & + & 0.34 & 0.34 & 0.34 \\
\hline & & $C_{21}$ & 养老保障 & 有养老金 $=2$, 无 $=1$ & + & 0.26 & 0.25 & 0.26 \\
\hline
\end{tabular}

表 2 样本村脱贫稳定性程度统计

Tab.2 Poverty alleviation sustainability degree of sample villages

\begin{tabular}{ccccc}
\hline 维度 & 稳定 & 较稳定 & 一般稳定 & 较不稳定 \\
\hline 自然资本 & 11.67 & 41.67 & 33.33 & 13.33 \\
经济条件 & 13.33 & 35.00 & 36.67 & 15.00 \\
人力资本 & 11.67 & 33.33 & 26.67 & 28.33 \\
发展机会 & 21.67 & 33.33 & 30.00 & 15.00 \\
社会保障 & 16.67 & 35.00 & 41.67 & 6.67 \\
综合维度 & 10.00 & 30.00 & 28.33 & 31.67 \\
\hline
\end{tabular}

岗乡胜利村, 咸宜乡双丰村、环流村, 明中乡金池 村, 廖子乡长元村, 庙坝镇排山村。主要归因于县 城西北地区位于大巴山脉南麓, 与川陕交界, 受地 理环境约束, 全乡土地脊薄、气候寒冷、地质环境脆 弱、山洪等自然灾害时有发生, 导致其对外交通及 生产要素流通等条件相对较差; 而南部地区则因平 均海拔较高、坡度大于 $25^{\circ}$ 耕地占比较大、耕地质量 较差等原因, 导致区域内部农业资源禀赋与其他区 域差异显著, 耕种成本较高, 不利于农业的规模化、
集约化发展,因此自然资本脱贫稳定性相对较低。

$$
\text { (2) 经济条件 }
$$

城口县经济条件脱贫稳定性指数值位于 0.330 0.933之间,均值为 0.641 , 可以看出该县各村 经济维度脱贫稳定性水平总体较高,但呈现区域分 异, 脱贫较不稳定、一般稳定、较稳定、稳定的村分 别占样本村总量的 $15.00 \%$ 、36.67\%、35.00\% 和 $13.33 \%$ 。经济条件维度的脱贫稳定性呈现“核心一 边缘结构”, 即以县政府所在地葛城街道为中心向 外围以 $5 \mathrm{~km}$ 为界展开缓冲区圈层划分, 发现经济维 度脱贫稳定性较低区域由中心向外围呈环状逐层 上升。经济维度脱贫稳定性高低受家庭人均纯收 人、转移性收人及增收情况等要素综合制约, 造成 外围地区脱贫稳定性较差的原因主要包括:一是距 离城中心较远, 受发展历史因素影响, 道路交通等 基础设施条件相对落后,资金投人、政策扶持等方 面与核心地区尚有差距,市场连通性较差; 二是受 经济高水平地区辐射带动作用小, 家庭成员外出务 
工及农产品外销等阻力较大、留守人口居多, 在招 商引资、信息交流、村集体建设等方面弱势显现。

(3) 人力资本

城口县人力资本脱贫稳定性指数值位于 0.259 0.924 之间, 均值为 0.635 , 可以看出各村人力 资本脱贫稳定性水平差异显著, 脱贫较不稳定、一 般稳定、较稳定、稳定的村分别占样本村总量的 $28.33 \% 、 26.67 \% 、 33.33 \%$ 和 $11.67 \%$ 。人力资本脱贫 稳定性指标受劳动力状况和健康水平等要素影响, 而城口县因病因残致贫比例较高, 家庭劳动力数量 稀缺、质量较低的农户群体空间分布广泛。脱贫较 不稳定村达 17 个, 占比在单维要素制约中位于最高 值, 其中稳定性指数最低值出现在明中乡云燕村。 实地调研发现, 脱贫户中多数劳动力的迁移范围限 于乡镇及县城, 依靠就近打零工等方式获取收人, 导致家庭收人稳定性欠佳且劳动力素质受损状况 突出, 成为脱贫攻坚的重点和难点。

(4) 发展机会

城口县发展机会脱贫稳定性指数值位于 0.144 0.881 之间, 均值为 0.523 , 稳定性水平总体居 中且各村发展机会不均衡, 脱贫较不稳定、一般稳 定、较稳定、稳定的村分别占样本村总量的 $15.00 \%$ 、 $30.00 \% 、 33.33 \%$ 和 $21.67 \%$ 。发展机会脱贫稳定性 受交通便利程度、受教育条件、政策性贷款支持和 劳动力技能培训等因素协同影响, 全县共 9 个村处 于脱贫较不稳定状态, 其中稳定性指数最低值出现 在东安乡密水村。发展机会脱贫稳定性较低的原 因主要包括村落区位因素制约、基础设施及公共服 务设施还需进一步完善、政策倾斜力度不一等, 导 致上学、出行、生产要素的流通、信息传递、发展政 策惠及度和关注度等均不同程度受阻, 潜在脱贫资 本较低、脱贫稳定性较差。

\section{(5) 社会保障}

城口县社会保障脱贫稳定性指数值位于 0.198 0.802 之间, 均值为 0.537 , 由于发展历史、民 族、地域等因素影响, 各村社会保障层面脱贫稳定 性水平不一且存在一定差距。脱贫较不稳定、一般 稳定、较稳定、稳定的村分别占样本村总量的 $6.67 \% 、 41.67 \% 、 35.00 \%$ 和 $16.67 \%$ 。可以看出, 因精 准扶贫政策的深人落实和全面小康社会的不断趋 近, 越来越多低收人、弱劳力群体得到关注, 随着普 惠性政策的广泛推进, 社会保障维度脱贫较不稳定 区域不断减少。除巴山镇黄溪村、治平乡新胜村、
厚坪乡麻柳村、岗天乡三河村因患病户数较多、医 疗支出相对较高导致脱贫较不稳定外, 脱贫稳定、 较稳定、一般稳定水平的村在县域内广泛分布。

综合 5 个维度的脱贫稳定性指数, 计算城口县 各样本村的综合脱贫稳定性指数(图 3f), 其中脱贫 较不稳定、一般稳定、较稳定、稳定的村分别占样本 村总量的 $31.67 \% 、 28.33 \% 、 30.00 \%$ 和 $10.00 \%$, 综合 脱贫稳定性指数值位于 $0.443 \sim 0.750$ 之间,均值为 0.570 。其中脱贫较不稳定的村包括县城西北地区 的巴山镇龙王村、农民村、黄溪村, 坪坝镇三湾村, 庙坝镇石兴村, 高燕乡星光村、青山村,西南地区的 鸡鸣乡金岩村、咸宜乡中六村, 东部地区的明中乡 云燕村、东安乡密水村、高观镇东红村和复兴村、厚 坪乡麻柳村、河鱼乡河鱼村、岗天乡三河村、北屏乡 松柏村及中部的苶子乡长湾村、葛城镇红坪村。不 难发现, 城口县多维脱贫稳定性总体不高, 且各村 稳定性指数呈现明显差异。

\section{2 返贫风险识别及模式划分}

贫困人口返贫风险是自然、经济、社会等多种 因素综合作用、交互影响的结果, 具有普遍广泛性、 地区差异性和可防可控性 ${ }^{[4]}$ 。为厘清各行政村返 贫风险, 找到稳定脱贫阻力, 并进一步对其防控和 管理,在对各村多维脱贫稳定性探析的基础上,利 用障碍度模型和最小方差模型(LSE), 结合自然资 本、经济条件、人力资本、发展机会和社会保障 5 个 维度的返贫风险贡献率得分, 划分不同返贫风险模 式和类型(表 3、表 4)。由表 3 可知, 在城口县样本村 返贫风险模式占比上, 四风险模式 $>$ 五风险模式 $>$ 三 风险模式>双风险模式, 而单风险模式样本村占比 为零。说明城口县各村均不同程度受潜在返贫风 险影响, 稳定脱贫阻力显现且风险因素复杂多样, 应识别各类阻力机理、针对不同模式的返贫风险, 因村施策、展开分类管理防控(图 4)。

\section{(1) 双风险模式}

双风险模式行政村占样本村总数的 $5.00 \%$, 数 量最少, 根据不同因子的风险贡献率可分为人力资 本一社会保障主导 $(\mathrm{H}-\mathrm{S}$ 型)和人力资本一发展机会 主导(H-D 型)2种类型。该类行政村在脱贫攻坚阶 段基础设施和公共服务设施逐步得到完善、农户经 济水平日益提升, 脱贫现阶段成果较好。但受固有 劳动力质量、受教育水平等短板效应影响, 农户增 收手段多以从事原始型、力量型或高危行业为主, 随年龄增长劳力减弱、突遇灾祸等内外部冲击导致 
(a) 自然资本

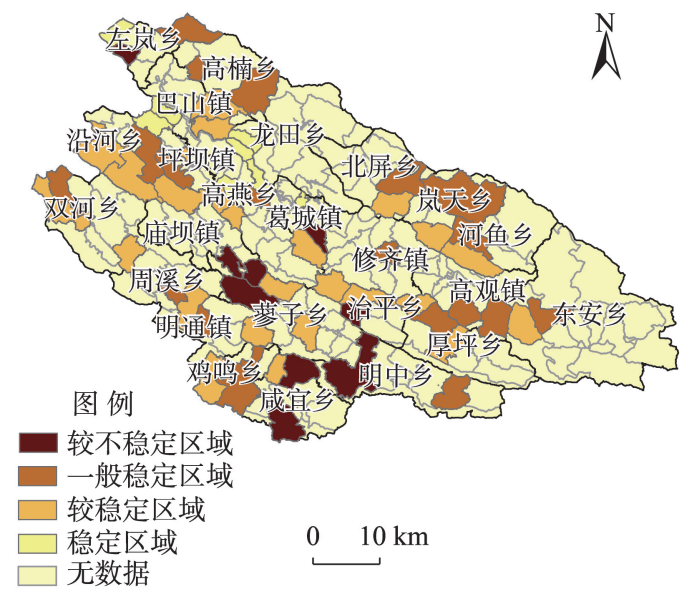

(c) 人力资本

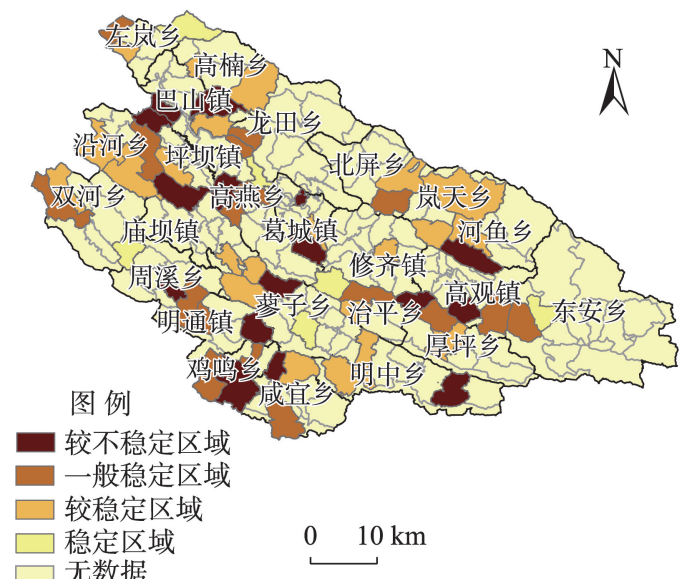

(e) 社会保障

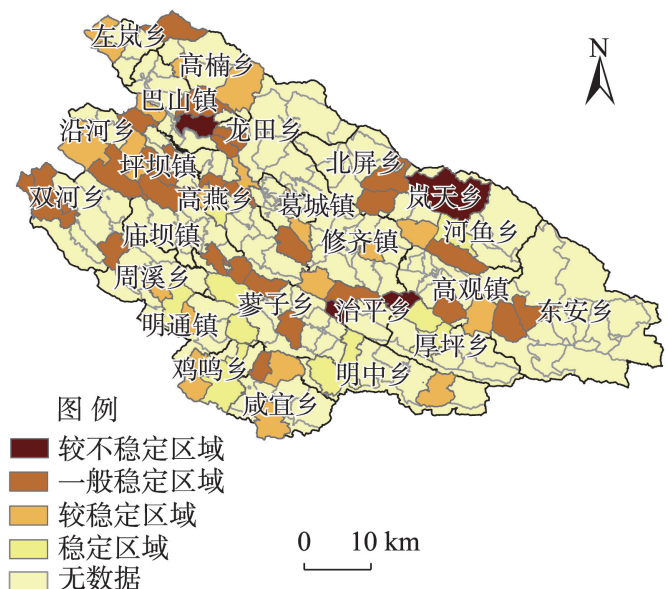

(b) 经济条件

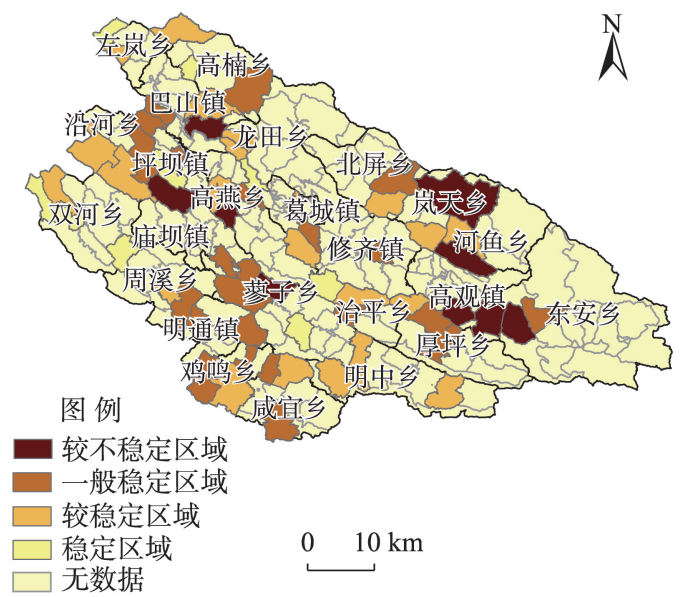

(d) 发展机会

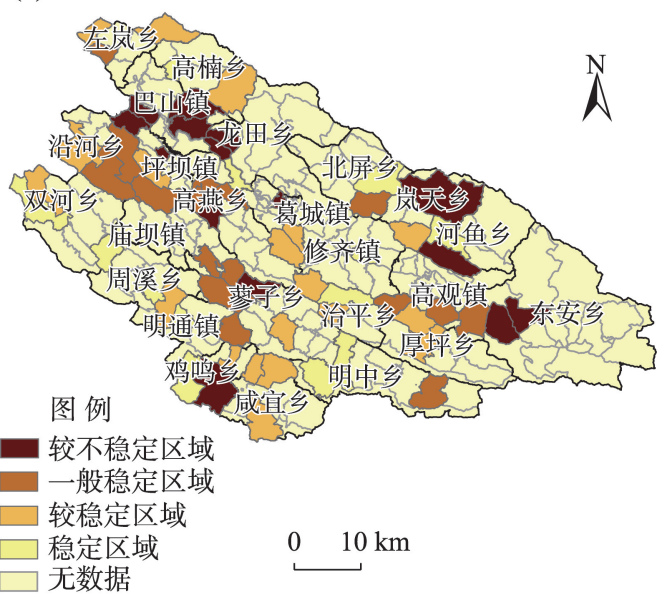

(f) 多维脱贫稳定性

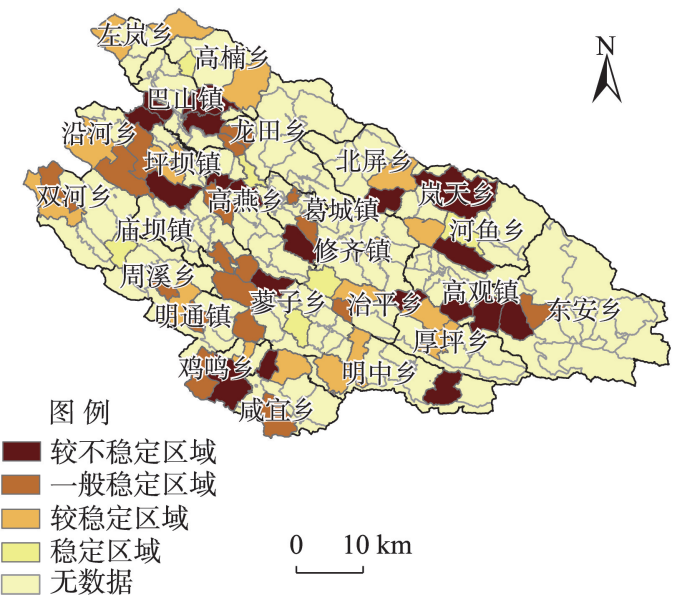

图 3 城口县样本村多维脱贫稳定性空间分布

Fig.3 Spatial distribution of multidimensional poverty alleviation sustainability of sample villages in Chengkou County

其返贫风险增加, 如金岩村劳动力质量较优家庭仅 占抽样农户总数的 $31.58 \%$, 而以基础力量型岗位为 主要增收渠道的家庭占 $26.32 \%$ 。

(2) 三风险模式

三风险模式行政村占样本村总数的 $21.67 \%$, 在
空间上整体呈现零散分布(图 5)。根据不同因子的 风险贡献率可分为自然资本一经济条件一人力资 本支配(N-E-H 型)、自然资本一人力资本一社会保 障支配 (N-H-S 型)、经济条件一人力资本一发展机 会支配(E-H-D 型)和人力资本一发展机会一社会保 
表 3 城口县样本村返贫风险模式统计

Tab.3 Return-to-poverty risk model statistics of sample villages in Chengkou County

(\%)

\begin{tabular}{ccccccc}
\hline $\begin{array}{c}\text { 返贫风险 } \\
\text { 模式 }\end{array}$ & 村占比 & $\begin{array}{c}\text { 自然资本主导 } \\
\text { 返贫风险占比 }\end{array}$ & $\begin{array}{c}\text { 经济条件主导 } \\
\text { 返贫风险占比 }\end{array}$ & $\begin{array}{c}\text { 人力资本主导 } \\
\text { 返贫风险占比 }\end{array}$ & $\begin{array}{c}\text { 发展机会主导 } \\
\text { 返贫风险占比 }\end{array}$ & $\begin{array}{c}\text { 社会保障主导 } \\
\text { 返贫风险占比 }\end{array}$ \\
\hline 单风险模式 & 0 & 0 & 0 & 0 & 0 & 0 \\
双风险模式 & 5.00 & 0 & 0 & 100.00 & 66.67 & 33.33 \\
三风险模式 & 21.67 & 23.08 & 46.15 & 100.00 & 76.92 & 53.85 \\
四风险模式 & 45.00 & 48.15 & 74.07 & 100.00 & 96.30 & 81.48 \\
五风险模式 & 28.33 & 100.00 & 100.00 & 100.00 & 100.00 & 100.00 \\
合计 & 100.00 & 55.00 & 71.67 & 100.00 & 91.67 & 78.33 \\
\hline
\end{tabular}

表 4 城口县样本村返贫风险类型划分

Tab.4 Return-to-poverty risk types of sample villages in Chengkou County

\begin{tabular}{cll}
\hline 返贫风险模式 & 返贫风险类型 & 地区 \\
\hline 双风险模式 & H-S 型 & 岩湾村 \\
& H-D型 & 红军村、金岩村 \\
三风险模式 & N-E-H型 & 金池村 \\
& N-H-S 型 & 大榜村、天星村 \\
& E-H-D型 & 东红村、双龙村、龙泉村、长田村、白鹤村 \\
& H-D-S型 & 仓房村、农民村、星光村、左岸村、红坪村 \\
& N-E-H-S 型 & 平安村 \\
& N-E-H-D型 & 茶坪村、平溪村、文峰村、熊竹村、长园村 \\
& N-H-D-S型 & 大兴村、聚马村、模式龙村、胜利村、团结村、永红村、云燕村 \\
& E-H-D-S 型 & 复兴村、黄溪村、河鱼村、龙王村、麻柳村、中安村、中六村、密水村、棉沙村、三湾村、石兴村、 \\
& 松柏村、瓦房村、长湾村 \\
& N-E-H-D-S型 & 北坡村、东河村、方斗村、环流村、金龙村、排山村、齐心村、青山村、三河村、柿坪村、双丰村、 \\
& & 双坪村、鲜花村、新胜村、星月村、竹园村、迎红村 \\
\hline
\end{tabular}

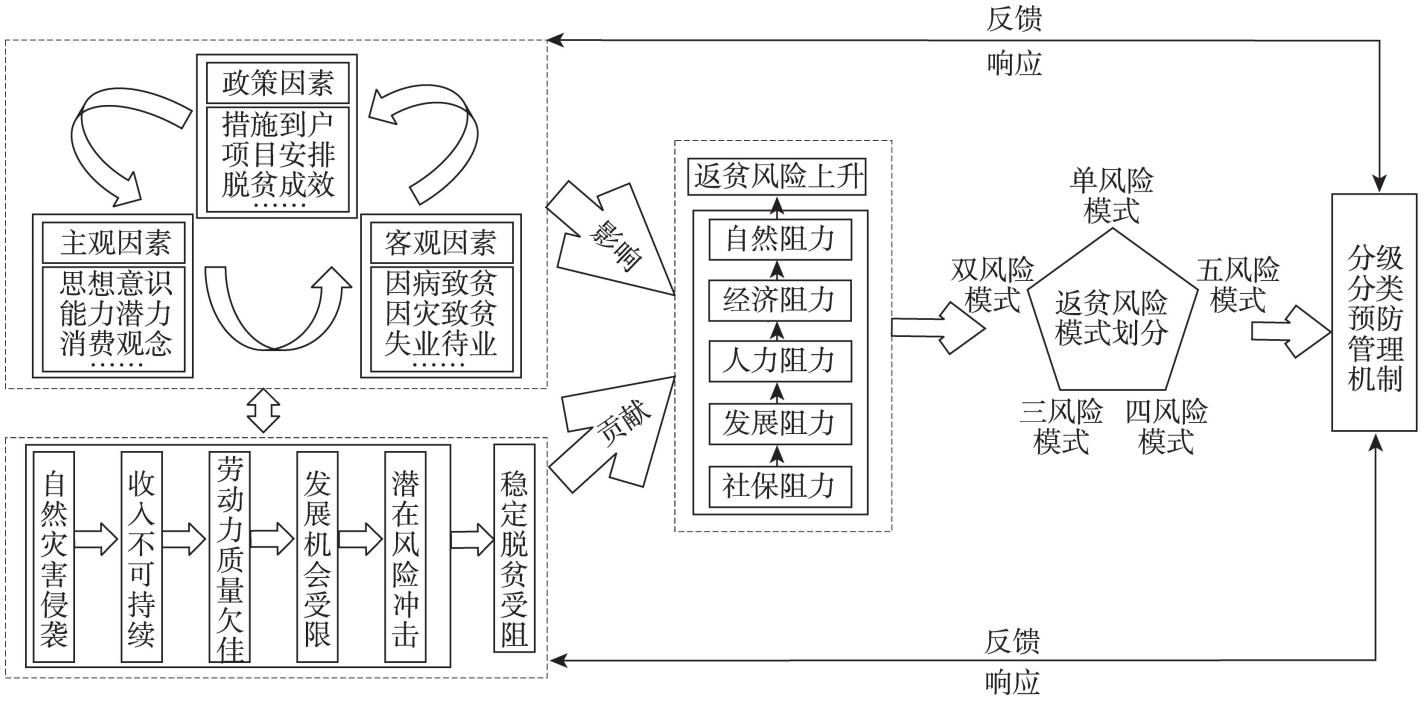

图4 返贫风险模式划分及防控机制分析

Fig.4 Return-to-poverty risk models and prevention and control mechanism 


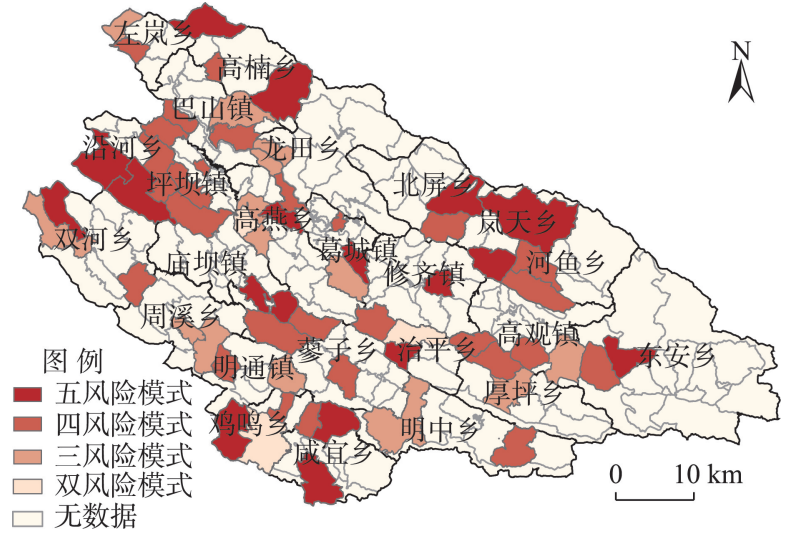

图 5 城口县样本村返贫风险模式空间分布

Fig.5 Spatial distribution of sample village return-to-poverty risk models, Chengkou County

障支配(H-D-S 型)4 种类型, 其中 E-H-D 型和 H-D-S 型为主要的三风险模式支配类型, 占该类模式村总 量的 $76.92 \%$ 。经济风险贡献率较高的村受政策惠 及,农户转移性收人占比相对较高, 产业帮扶多以 分红、补贴等形式开展, 未能形成长效稳定的利益 联结机制; 如经济因子风险贡献率最高的长田村， 转移性收人占比超过家庭总收人 $50 \%$ 的农户为 $17.95 \%$, 创收能力与收人可持续性存在风险。同时 该模式下部分村因空巢老人、残疾群体及精神障碍 患者等特殊困难群体相对较多, 导致产业辐射带动 能力较弱、各类劳动力技能培训效果不明显, 农户 自身发展动力和抗风险能力有待进一步提升。

(3) 四风险模式

四风险模式行政村占样本村总数的 $45.00 \%$, 在 各风险模式中数量最多、占比最高。该模式样本村 空间分布广泛, 根据不同因子的风险贡献率可分为 自然资本一经济条件一人力资本一社会保障协同 (N-E-H-S 型)、自然资本一经济条件一人力资本一 发展机会协同 (N-E-H-D 型)、自然资本一人力资本 一发展机会一社会保障协同(N-H-D-S 型)和经济条 件一人力资本一发展机会一社会保障协同(E-H-D$\mathrm{S}$ 型)4种类型。从各村脱贫稳定性来看, 其稳定性 指数明显低于全县平均水平, 返贫风险较大。由于 贫困群体留守比例较高, 对看病就医条件、教育条 件和交通便利程度的要求较高, 同时个别地区受平 均海拔较高、耕地质量较差、地质灾害易发等自然 条件限制, 如自然风险贡献率较高的长园村地质灾 害易发性比各村均值高出 1.28 个百分点, 云燕村平 均海拔为抽样村平均海拔的 1.30 倍, 部分农户以农 业为唯一收人途径略为单一且抗击风险能力差, 对
政策性贷款支持、劳动技能的培养提升和集体涓滴 效应的需求相对迫切。

(4) 五风险模式

五风险模式行政村占样本村总数的 $28.33 \%$, 为 自然资本、经济条件、人力资本、发展机会和社会保 障多风险因子共同作用构成的 N-E-H-D-S 型。该 类型行政村返贫风险多样,但各因素返贫风险贡献 率相对均衡,在空间上主要分布于县城外围及行政 边界邻近区域。

总体来看, 各村返贫风险模式因子贡献率中, 人力资本贡献率 $>$ 发展机会贡献率 $>$ 社会保障贡献 率 $>$ 经济条件贡献率 $>$ 自然资源贡献率。可以看出 现阶段返贫风险的防控与贫困人口、贫困村的初期 识别侧重点出现分异, 随着脱贫攻坚各项政策的不 断推进和成果提升, 自然资本和经济条件已不再是 导致稳定脱贫受阻的主要因素, 而人力资本、发展 机会等涉及农户可持续增收、动态抗风险能力和内 生动力的要素逐渐成为减贫防贫路径依赖的重点。

\section{3 返贫防控机制分析}

(1) 对于双风险及三风险模式的行政村,在确 保帮扶力量不减退的前提下, 加强贫困户教育引 导, 增强群众发展的内生动力, 提高农村劳动力转 移的组织化程度, 着力提升农户可持续增收能力和 “造血”功能。对村内 “输出”劳动力进行健康状况 定期问询,使突发大病或遭遇横祸的农户可及时得 到医疗救助和帮扶; 同时积极开拓就近就业渠道, 通过土地流转、参与合作社生产经营等方式争取为 “内守”的家庭人口实现家门口就业, 以期提高农户 抗风险能力, 实现收人稳定可持续, 化解返贫风 险。加强对农村最低生活保障和扶贫开发政策 2 项 制度衔接的关注, 及时进行低保等政策动态调整并 确保公正公开,杜绝“错保” “漏保”等现象发生, 注 重保障政策的连续性,在精准识别的基础上, 随经 济社会发展逐步上调各项政策标准线,提升医疗和 教育水平, 形成兒住贫困人口脱贫、降低返贫风险 的“安全网”。

(2) 对于四风险模式的行政村,继续攻坚和防 止返贫应双管齐下,在规划开发时根据各区自然条 件因地制宜、扬长避短, 适当提高生态补偿标准, 着 力解决因自然生存环境恶化而导致的返贫问题; 同 时不断提升教育、医疗、交通等基础设施和公共服 务设施保障水平, 加大扶贫政策宣传力度, 挖掘当 地优势产业, 找准户、村、企合作的典型模式, 盘活 
农村集体资源、资产和资金,努力寻求多样化发展, 为巩固提升脱贫成果、实现稳定脱贫打下坚实基础。

(3) 对于高于多维脱贫稳定性指数平均值的五 风险模式村,其脱贫质量尚佳、整体发展条件较好, 返贫风险相对较小; 而稳定性指数低于样本村平均 值的五风险模式村, 应加大其返贫防控力度, 各个 因素逐一击破, 加深脱贫成效, 同时在治理过程中 注重综合多个因素的联动和多向反馈, 积极采取应 对措施,稳步降低返贫风险。

\section{5 结论与讨论}

秦巴山区作为全国集中连片特困地区之一, 是 脱贫攻坚的主战场和脱贫返贫的高发区。城口县 受大巴山特殊地形条件及地理位置影响, 集“老、 边、山、穷”于一体, 对探析山区脱贫稳定性分异特 征及返贫风险防控具有典型意义。本文以重庆市 城口县为例, 利用多维脱贫稳定性测度模型、障碍 度模型和最小方差模型等从自然资本、经济条件、 人力资本、发展机会、社会保障 5 个维度构建村域多 维脱贫稳定性测度指标体系, 探究其区域分异机 制, 并根据各因子的返贫风险贡献率进行返贫风险 模式和类型划分, 主要结论如下:

(1) 按自然断点法将城口县多维脱贫稳定性水 平划分为稳定、较稳定、一般稳定和较不稳定 4 个等 级, 样本村脱贫稳定性等级分布总体呈现前端窄 小、中部突出的 “葫芦状”结构; 城口县各地区多维 脱贫稳定性总体不高且存在空间异质性。

(2) 城口县返贫风险可识别为双风险模式、三 风险模式、四风险模式和五风险模式 4 种模式及各 阻力因素多元整合主导的 11 种返贫风险类型。其 中四风险模式行政村分布广泛, 各因子中以人力资 本返贫风险贡献率最高。可以看出, 各村返贫风险 受多因素制约且存在差异, 人力资本、发展机会等 涉及农户可持续增收、发展能力和内生动力的要素 逐渐成为现阶段返贫防控及减贫路径依赖的重点。

(3) 根据城口县多维脱贫稳定性分异规律及返 贫风险模式, 为精准扶贫及实现稳定脱贫提出建 议: 把继续攻坚和稳定脱贫、防止返贫摆在同等重 要位置上, 依照差异化原则, 因村施策发展产业、盘 活资源, 对转移劳动力和留守人群双管齐下, 激发 群众内生动力、提高抗风险能力, 精准织密防止脱 贫群体的返贫网。

本文针对城口县展开脱贫稳定性测度, 探析其
区域分异机制并划分各村返贫风险类型，旨在为后 精准扶贫时代实现山区贫困人口稳定脱贫、精准施 策防止返贫提供决策参考。限于数据的可获取性, 所有分析基于静态数据, 缺乏加人时间序列的面板 数据对脱贫稳定性的时空演变特征及更深层次的 返贫风险机理进行探讨。在后续研究中, 可对上述 不足进行丰富完善, 以期为实现稳定脱贫、化解返 贫风险进一步提供方向和思路。

\section{参考文献(References)}

[1] 万良杰, 万铭师. 民族地区贫困脆弱性测度 [J]. 统计与决 策, 2021(3): 21-24. [Wan Liangjie, Wan Mingshi. Poverty vulnerability measurement in ethnic minority areas. Statistics \& Decision, 2021(3): 21-24. ]

[2] 刘彦随, 周扬, 刘继来. 中国农村贫困化地域分异特征及 其精准扶贫策略 [J]. 中国科学院院刊, 2016, 31(3): 269278. [Liu Yansui, Zhou Yang, Liu Jilai. Regional differentiation characteristics of rural poverty and targeted poverty alleviation strategy in China. Bulletin of Chinese Academy of Sciences, 2016, 31(3): 269-278. ]

[3] 蔡进, 禹洋春, 骆东奇, 等. 重庆市农村多维贫困空间分 异及影响因素分析 [J]. 农业工程学报, 2018, 34(22): 235-245. [Cai Jin, Yu Yangchun, Luo Dongqi, et al. Space differentiation and its influence factor analysis of rural multidimensional poverty in Chongqing. Transactions of the CSAE, 2018, 34(22): 235-245. ]

[4] 刘彦随, 曹智. 精准扶贫供给侧结构及其改革策略 [J]. 中国科学院院刊, 2017, 32(10): 1066-1073. [Liu Yansui, Cao Zhi. Supply-side structural reform and its strategy for targeted poverty alleviation in China. Bulletin of Chinese Academy of Sciences, 2017, 32(10): 1066-1073. ]

[5] 刘彦随, 李进涛. 中国县域农村贫困化分异机制的地理 探测与优化决策 [J]. 地理学报, 2017, 72(1): 161-173. [Liu Yansui, Li Jintao. Geographic detection and optimizing decision of the differentiation mechanism of rural poverty in China. Acta Geographica Sinica, 2017, 72(1): 161-173. ]

[6] 胡原, 曾维忠. 深度贫困地区何以稳定脱贫? 基于可持续 生计分析框架的现实思考 [J]. 当代经济管理, 2019, 41 (12): 7-12. [Hu Yuan, Zeng Weizhong. How to help the deep poverty-stricken areas stably get out of poverty?: Realistic thinking based on the framework of sustainable livelihood analysis. Contemporary Economy \& Management, 2019, 41(12): 7-12. ]

[7] 冷志明, 雷亿辉. 基于新区域主义的我国连片贫困区开 发研究 [J]. 经济地理, 2011, 31(4): 646-650. [Leng Zhiming, Lei Yihui. Development research of continuous poor areas of our country based on new regionalism. Economic Geography, 2011, 31(4): 646-650. ] 
[8] 王小林. 贫困标准及全球贫困状况 [J]. 经济研究参考, 2012(55): 41-50. [Wang Xiaolin. Poverty standards and global poverty. Review of Economic Research, 2012(55): 41-50. ]

[9] Deutsch J, Silber J. Measuring multidimensional poverty: An empirical comparison of various approaches [J]. Review of Income and Wealth, 2005, 51(1): 145-174.

[10] Daimon T. The spatial dimension of welfare and poverty: Lessons from a regional targeting programme in Indonesia [J]. Asian Economic Journal, 2001, 15(4): 345-367.

[11] Jalan J, Ravallion M. Geographic poverty traps? A micro model of consumption growth in rural China [J]. Journal of Applied Econometrics, 2002, 17(4): 329-346.

[12] Bird K, Shepherd A. Livelihoods and chronic poverty in semi-arid Zimbabwe [J]. World Development, 2003, 31 (3): 591-610.

[13] Park A, Wang S G, Wu G B. Regional poverty targeting in China [J]. Journal of Public Economics, 2002, 86(1): 123-153.

[14] 王婷. 贫困内涵及贫困标准问题探讨 [J]. 固原师专学 报, 2003, 24(1): 89-92. [Wang Ting. The discuss of connotation and standard of poverty. Journal of Guyuan Teachers College, 2003, 24(1): 89-92. ]

[15] 胡德海. 准确理解贫困内涵 科学解决贫困问题 [J]. 农 村经济与技术, 2003(12): 7-8. [Hu Dehai. Accurately understand the connotation of poverty and solve poverty problems scientifically. Rural Economy and Technlogy, 2003(12): 7-8. ]

[16] 高开华, 卢士仁. 试析贫困地区温饱的内涵 [J]. 老区建 设, 1990(8): 19-20. [Gao Kaihua, Lu Shiren. On the connotation of food and clothing in poor areas. Construction of the Old Revolutionary Area, 1990(8): 19-20. ]

[17] 胡原, 卢冲, 曾维忠. 四省藏区多维贫困空间分异及基 层能力建设 [J]. 经济地理, 2020, 40(2): 171- 180. [Hu Yuan, Lu Chong, Zeng Weizhong. Research on multidimensional poverty and capability in Tibetan areas in four provinces. Economic Geography, 2020, 40(2): 171-180. ]

[18] 刘艳华, 徐勇. 中国农村多维贫困地理识别及类型划分 [J]. 地理学报, 2015, 70(6): 993-1007. [Liu Yanhua, Xu Yong. Geographical identification and classification of multi- dimensional poverty in rural China. Acta Geographica Sinica, 2015, 70(6): 993-1007. ]

[19] 刘愿理, 廖和平, 张茜茜, 等. 西南喀斯特区贫困空间剥 夺的识别及空间格局分析 [J]. 农业工程学报, 2019, 35 (15): 284-294. [Liu Yuanli, Liao Heping, Zhang Qianqian, et al. Identification and spatial pattern analysis of poverty spatial deprivation in karst region of Southwest China. Transactions of the CSAE, 2019, 35(15): 284-294. ]

[20] 何仁伟, 方方, 刘运伟. 贫困山区农户人力资本对生计
策略的影响研究: 以四川省凉山彝族自治州为例 [J]. 地理科学进展, 2019, 38(9): 1282-1293. [He Renwei, Fang fang, Liu Yunwei. Influence of human capital on the livelihood strategy of farming households in poor mountainous areas: A case study of Liangshan Yi Autonomous Prefecture of Sichuan, China. Progress in Geography, 2019, 38(9): 1282-1293. ]

[21] 孙林, 王艳慧, 柯文俊, 等. 内蒙古自治区农村人口多维 贫困特征测算与分析 [J]. 人文地理, 2016, 31(1): 108115, 146. [Sun Lin, Wang Yanhui, Ke Wenjun, et al. A study on the characteristics of multidimensional poverty in the Mongolia Autonomous Region. Human Geography, 2016, 31(1): 108-115, 146. ]

[22] 冯应斌, 龙花楼. 基于乡村人口转移和农村道路建设的 空间贫困破解机理及其对策研究: 以贵州省为例 [J]. 地理研究, 2019，38(11): 2606-2623. [Feng Yingbin, Long Hualou. The mechanism and countermeasures of solving spatial poverty based on rural population transfer and rural road construction: A case study of Guizhou Province. Geographical Research, 2019, 38(11): 2606-2623. ]

[23] 王群, 银马华, 杨兴柱, 等. 大别山贫困区旅游地社会一 生态系统脆弱性时空演变与影响机理 [J]. 地理学报, 2019, 74(8): 1663-1679. [Wang Qun, Yin Mahua, Yang Xingzhu, et al. Spatio- temporal evolution and impact mechanism of socio- ecological system vulnerability in poor mountainous tourist distinations: Taking Dabie Mountain area as example. Acta Geographica Sinica, 2019, 74(8): 1663-1679. ]

[24] 王昭, 刘建红, 李同昇, 等. 秦巴特困区生态脆弱性与经 济贫困的耦合关系: 以陕西省山阳县为例 [J]. 生态学 报, 2019, 39(11): 3908-3917. [Wang Zhao, Liu Jianhong, Li Tongsheng, et al. Analysis of the coupling relationship between ecological vulnerability and economic poverty in Qinling-Dabashan contiguous poor areas: A case study of Shanyang County in Shaanxi Province, China. Acta Ecologica Sinica, 2019, 39(11): 3908-3917. ]

[25] 杨园园, 刘彦随, 张紫雯. 基于典型调查的精准扶贫政 策创新及建议 [J]. 中国科学院院刊, 2016, 31(3): 337345. [Yang Yuanyuan, Liu Yansui, Zhang Ziwen. Study on policy innovation and suggestions of targeted poverty alleviation based on typical investigation. Bulletin of Chinese Academy of Sciences, 2016, 31(3): 337-345. ]

[26] 鲁大铭, 杨新军, 石育中, 等. 黄土高原乡村体制转换与 转型发展 [J]. 地理学报, 2020, 75(2): 348- 364. [ [ Lu Daming, Yang Xinjun, Shi Yuzhong, et al. Rural regime shifts and transformation development on the Loess Plateau. Acta Geographica Sinica, 2020, 75(2): 348-364. ]

[27] 马历, 龙花楼, 屠爽爽, 等. 基于乡村多功能理论的贫困 村域演变特征与振兴路径探讨: 以海南省什寒村为例 
[J]. 地理科学进展, 2019, 38(9): 1435-1446. [Ma Li, Long Hualou, Tu Shuangshuang, et al. Characteristics of change and vitalization pathways of poor villages based on multifunctional rural development theory: A case study of Zahan Village in Hainan Province. Progress in Geography, 2019, 38(9): 1435-1446. ]

[28] 刘小鹏, 李伟华, 王鹏, 等. 发展地理学视角下欠发达地 区贫困的地方分异与治理 [J]. 地理学报, 2019, 74(10): 2108-2122. [Liu Xiaopeng, Li Weihua, Wang Peng, et al. Local differentiation and alleviation of poverty in underdeveloped areas based on development geography. Acta Geographica Sinica, 2019, 74(10): 2108-2122. ]

[29] 刘小鹏, 马存霞, 魏丽, 等. 黄河上游地区减贫转向与高 质量发展 [J]. 资源科学, 2020, 42(1): 197-205. [Liu Xiaopeng, Ma Cunxia, Wei Li, et al. Poverty reduction turn and high-quality development in the upper reaches of the Yellow River. Resources Science, 2020, 42(1): 197-205. ]

[30] 朱永甜, 余劲. 陕南易地扶贫搬迁减贫效应研究: 基于 分阶段的讨论 [J]. 干旱区资源与环境, 2020, 34(5): 6469. [Zhu Yongtian, Yu Jin. Effect of poverty alleviation relocation in southern Shaanxi Province. Journal of Arid Land Resources and Environment, 2020, 34(5): 64-69. ]

[31] 胡原, 曾维忠. 稳定脱贫的科学内涵、现实困境与机制 重构: 基于可持续生计一脆弱性一社会排斥分析框架 [J]. 四川师范大学学报(社会科学版), 2019, 46(5): 121128. [Hu Yuan, Zeng Weizhong. Scientific connotation, realistic dilemma and mechanism reconstruction of stabilization out of poverty: An analytical framework on sustainable livelihoods, vulnerability and social exclusion. Journal of Sichuan Normal University (Social Sciences Edition), 2019, 46(5): 121-128. ]

[32] 杨龙, 汪三贵. 贫困地区农户脆弱性及其影响因素分析 [J]. 中国人口・资源与环境, 2015, 25(10): 150-156. [Yang Long, Wang Sangui. Households' vulnerability and determinants analysis in poor areas. China Population, Resources and Environment, 2015, 25(10): 150-156. ]

[33] 吴仪, 林月, 祁新华. 福建省返贫脆弱性的时空演变特 征与产生机制 [J]. 福建农业学报, 2019, 34(8): 985993. [Wu Yi, Lin Yue, Qi Xinhua. Temporal-spatial evolution and vulnerability of return- to- poverty after successful implementation of alleviation program in Fujian. Fujian Journal of Agricultural Sciences, 2019, 34(8): 985993. ]

[34] 王富珍, 周国华, 唐承丽, 等. 基于可持续生计分析框架 的山区县域脱贫稳定性评价 [J]. 农业工程学报, 2019, 35(2): 270- 277. [Wang Fuzhen, Zhou Guohua, Tang Chengli, et al. Evaluation of poverty alleviation stability in poverty stricken counties in mountainous areas based on framework of sustainable livelihood analysis. Transactions of the CSAE, 2019, 35(2): 270-277. ]

[35] 李靖. 基于 SL 拓展框架的贫困农户生计空间差异与影 响因素研究 [D]. 重庆: 西南大学, 2018. [Li Jing. Study on the spatial differences and influencing factors of poor rural households' livelihood based on the expanded sustainable livelihood framework. Chongqing, China: Southwest University, 2018. ]

[36] 罗刚, 廖和平, 李涛, 等. 地理资本视角下村级多维贫困 测度及贫困类型划分: 基于重庆市 1919 个市级贫困村 调研数据 [J]. 中国农业资源与区划, 2018, 39(8): 244254. [Luo Gang, Liao Heping, Li Tao, et al. Measurement and classification for multi-dimensional poverty of poor villages from the perspective of geographical capital: Based on field survey data of 1919 poverty-stricken villages in Chongqing. Chinese Journal of Agricultural Resources and Regional Planning, 2018, 39(8): 244254. ]

[37] 孙才志, 董璐, 郑德风. 中国农村水贫困风险评价、障碍 因子及阻力类型分析 [J]. 资源科学, 2014, 36(5): 895905. [Sun Caizhi, Dong Lu, Zheng Defeng. Rural water poverty risk evaluation, obstacle indicators and resistance paradigms in China. Resources Science, 2014, 36 (5): 895-905. ]

[38] 张耀光. 最小方差在农业类型(或农业区)划分中的应 用: 以我国粮食作物结构类型划分为例 [J]. 经济地理, 1986, 6(1): 49-55. [Zhang Yaoguang. The application of minimum variance in agricultural classification: Take the structure type division of grain crops in China as an example. Economic Geography, 1986, 6(1): 49-55. ]

[39] 张建勋, 夏咏. 深度贫困地区多维贫困测度与时空分异 特征: 来自新疆南疆四地州的证据 [J]. 干早区资源与 环境, 2020, 34(4): 88-93. [Zhang Jianxun, Xia Yong. Multidimensional poverty measurement and spatial- temporal differentiation characteristics in the poverty- stricken areas-evidence from the four regions in southern Xinjiang. Journal of Arid Land Resources and Environment, 2020, 34(4): 88-93. ]

[40] 陈秧分, 刘玉, 王国刚. 大都市乡村发展比较及其对乡 村振兴战略的启示 [J]. 地理科学进展, 2019, 38(9): 1403-1411. [Chen Yangfen, Liu Yu, Wang Guogang. Rural development in metropolitan areas and implications for rural vitalization strategy. Progress in Geography, 2019, 38(9): 1403-1411. ]

[41] 刘愿理, 廖和平, 李涛, 等. 山区土地利用多功能时空分 异特征及影响因素分析 [J]. 农业工程学报, 2019, 35 (21): 271-279. [Liu Yuanli, Liao Heping, Li Tao, et al. Spatio- temporal diversity and influencing factors of multi- functionality of land use in mountainous regions. 
Transactions of the CSAE, 2019, 35(21): 271- 279. ]

[42] 黄晓军, 王晨, 胡凯丽. 快速空间扩张下西安市边缘区 社会脆弱性多尺度评估 [J]. 地理学报, 2018, 73(6) 1002- 1017. [Huang Xiaojun, Wang Chen, Hu Kaili. Multi-scale assessment of social vulnerability to rapid urban expansion in urban fringe: A case study of Xi'an. Acta Geographica Sinica, 2018, 73(6): 1002-1017. ]

[43] 王星. 双车道公路弯坡路段交通安全评估及处治措施 研究 [D]. 重庆: 重庆交通大学, 2014. [Wang Xing. Twolane curved slope road traffic safety evaluation research and treatment measures. Chongqing, China: Chongqing Jiaotong University, 2014. ]

[44] 蒋应刚, 朱昌丽, 张继飞. 西藏贫困的脆弱性和多维性: 以昌都、日喀则为例 [J]. 中国农业资源与区划, 2020, 41(12): 92-101. [Jiang Yinggang, Zhu Changli, Zhang Jifei. Vulnerability and multidimensionality of poverty in Tibet: A case study in Fando and Xigaze. Chinese Journal of Agricultural Resources and Regional Planning, 2020, 41
(12): 92-101. ]

[45] 蒋佩华. 重庆市城口县山洪灾害成因分析及对策研究 [D]. 重庆: 西南大学, 2007. [Jiang Peihua. A study on formation reasons about Chengkou County's mountain torrent diasters and countermeasures. Chongqing, China: Southwest University, 2007. ]

[46] 孙晗霖, 刘新智, 张鹏瑶. 贫困地区精准脱贫户生计可 持续及其动态风险研究 $[\mathrm{J}]$. 中国人口・资源与环境, 2019, 29(2): 145-155. [Sun Hanlin, Liu Xinzhi, Zhang Pengyao. Study on livelihood sustainability and its dynamic risk of targeted poverty-alleviation households in poverty-stricken areas. China Population, Resources and Environment, 2019, 29(2): 145-155. ]

[47] 张鹏飞. 关于返贫防控机制建设的几点思考 [J]. 法制 与 社 会, 2017(33): 128- 129. [Zhang Pengfei. Some thoughts on the prevention and control mechanism construction of poverty alleviation. Legal System and Society, 2017(33): 128-129. ]

\title{
Measurement of rural poverty alleviation sustainability and return-to-poverty risk identification in Qinling-Bashan Mountains: A case study of Chengkou County, Chongqing Municipality
}

\author{
GUO Qian', LIAO Heping ${ }^{1,2^{*}}$, WANG Ziyi ${ }^{1}$, LIU Yuanli', LI Tao ${ }^{1}$ \\ (1. School of Geographical Science, Southwest University, Chongqing 400715, China;
}

2. Center for Targeted Poverty Alleviation and Regional Development Assessment, Chongqing 400715, China)

\begin{abstract}
Achieving sustainable poverty alleviation and establishing a prevention and control mechanism for return-to-poverty in extreme poverty rural areas is a realistic requirement in the post-2020 era. It is also a key link between precision poverty alleviation and rural revitalization. Taking Chengkou County of Chongqing Municipality - an area of strong ecological fragility and concentrated continuous poverty - as the research area, and based on the poverty alleviation sustainability measurement model, obstacle degree model, and minimum variance model, this study explored the spatial differentiation of multidimensional poverty alleviation sustainability and the return-to-poverty risk models for 60 villages and 1950 farming households in the area. The study found that: 1) The sample villages' poverty alleviation sustainability distribution generally showed a "gourd- like" structure where the front end is narrow and the middle part protrudes. The multidimensional poverty alleviation sustainability in the area is generally low and of different degrees. 2) The return-to-poverty risk in Chengkou County can be divided into four models and 11 types, dominated by diversified integration of various resistance factors. Human capital, development opportunities, and other factors related to sustainable income growth, dynamic anti-risk capability, and endogenous drives of farmers have gradually become the focus of poverty reduction and control of return- to- poverty at this stage. 3) Local governments should give equal priority to alleviating poverty, improving the sustainability of poverty alleviation, and preventing return- topoverty. At the same time, improve people's ability to resist risks and develop a network for preventing return-topoverty of vulnerable groups with specific policy in each village.
\end{abstract}

Keywords: village space; sustainable poverty alleviation; return-to-poverty risk model; spatial differentiation; post-2020 era; Qinling-Bashan Mountains 